\title{
Sinopsis y novedades taxonómicas de la familia Marantaceae en la Argentina, incluyendo una nueVa cita para el Paraguay
}

\author{
CHRISTIAN A. ZANOTTI'1 JUAN C. OSPINA ${ }^{1}$ y HÉCTOR A. KELLER²
}

\begin{abstract}
Summary: A synopsis and taxonomic novelties of the family Marantaceae in Argentina, including a new record from Paraguay. This synopsis of the Argentine species of Marantaceae includes six genera and seven species: Ctenanthe muelleri, Goeppertia eichleri, Maranta sobolifera, Saranthe eichleri, Stromanthe boliviana, Thalia geniculata, and T. multiflora. Species Ctenanthe muelleri is cited for the first time for Argentina and Paraguay, and Saranthe eichleri as a new record for Argentina. Ctenanthe casupoides var. subtropicalis is here synonymyzed within Saranthe eichleri. Lectotypes are designated for Calathea eichleri, C. macrostachya, Saranthe eichleri, and Thalia geniculata. Treatment of each species includes synonyms, iconography, vernacular names, observations, ethnobotany, geographical distribution, and habitat, and examined material. A key to the species, some illustrations and field photographs are also provided.
\end{abstract}

Key words: Ctenanthe muelleri, lectotypifications, new records, Saranthe eichleri, South America.

\begin{abstract}
Resumen: Se presenta una sinopsis de la familia Marantaceae para la Argentina, donde se incluyen seis géneros y siete especies: Ctenanthe muelleri, Goeppertia eichleri, Maranta sobolifera, Saranthe eichleri, Stromanthe boliviana, Thalia geniculata y T. multiflora. La especie Ctenanthe muelleri es citada por primera vez para la Argentina y el Paraguay, y Saranthe eichleri es registrada por primera vez para la Argentina. Ctenanthe casupoides var. subtropicalis es aquí sinonimizado en Saranthe eichleri. Se designan lectotipos para Calathea eichleri, C. macrostachya, Saranthe eichleri y Thalia geniculata. El tratamiento de cada especie incluye sinónimos, iconografía, nombres vulgares, observaciones, etnobotánica, distribución geográfica y hábitat, y material examinado. También se proveen una clave para las especies, algunas ilustraciones y fotografías de campo.
\end{abstract}

Palabras clave: Ctenanthe muelleri, lectotipificaciones, nuevos registros, Saranthe eichleri, Sudamérica.

\section{INTRODUCCIÓN}

Marantaceae R. Br., nom. cons., en una familia de monocotiledóneas de distribución pantropical, con aproximadamente 550 especies agrupadas en 32 géneros (Andersson, 1998; Borchsenius et al., 2012), probablemente de origen africano

\footnotetext{
1 Instituto de Botánica Darwinion, IBODA-CONICET, Casilla de Correo 22, B1642HYD, San Isidro, Buenos Aires, Argentina. E-mail: czanotti@darwin.edu.ar (autor corresponsal).

2 Instituto de Botánica del Nordeste, UNNE-CONICET, Casilla de Correo 209, 3400, Corrientes, Argentina.
}

(Andersson \& Chase, 2001) y con una posterior dispersión al sudeste de Asia y al Nuevo Mundo (Ley \& Claßen-Bockhoff, 2011). La mayor riqueza específica se encuentra en los bosques y selvas neotropicales con alrededor de 450 especies (Prince \& Kress, 2006a, b), siendo Brasil el país con la mayor diversidad (Braga, 2005; Borchsenius et al., 2012). Esta familia se caracteriza por presentar un sistema avanzado de polinización con estructuras estaminales especializadas, láminas con venas secundarias sigmoideas y un pulvínulo en la unión entre la lámina y el pecíolo que permite el cambio de orientación de la lámina de acuerdo a la intensidad y el ángulo de la luz del sol (Judd et al., 1999; 
Suksathan et al., 2009). Marantaceae forma un grupo monofilético dentro del orden Zingiberales, bien sustentado por caracteres morfológicos (Andersson, 1981a) y moleculares (Kress, 1990, 1995; Smith et al., 1993; Kress et al., 2001; Sass et al., 2016). Sin embargo, la circunscripción de la mayoría de los géneros, y en consecuencia, las relaciones filogenéticas dentro de la familia, hasta el momento, no están lo suficientemente claras (Judd et al., 1999; Andersson \& Chase, 2001; Prince \& Kress, 2006a). No obstante, recientes estudios filogenéticos moleculares han dado como resultado la recircunscripción de algunos de los géneros de Marantaceae. (e.g. Suksathan et al., 2009; Borchsenius et al., 2012).

La única contribución taxonómica completa de la familia fue realizada por Schumann (1902). Sin embargo, este trabajo, ha sido cuestionado por la dificultad que muestra en la delimitación genérica (Anderson, 1981a), y esta misma falta de límites claros se da también a nivel específico (Andersson, 1986; Zanotti et al., 2017). Este problema es secundado por la existencia de revisiones taxonómicas en tesis doctorales no publicadas, y de difícil acceso, (Yoshida-Arns, 2003; Uliana, 2005; Vieira, 2005; Saka, 2016). No obstante, otros géneros del área presentan revisiones relativamente recientes (Andersson, 1977, 1981b, 1986; Hagberg \& Eriksson, 2011; Vieira et al., 2012a).

En el marco del proyecto Flora Argentina en desarrollo en el Instituto de Botánica Darwinion, y durante la identificación de ejemplares provenientes de la provincia de Misiones se concluyó que era necesario proveer una sinopsis de la familia Marantaceae, junto con una clave dicotómica, que permita aclarar la taxonomía de las especies que crecen en el territorio argentino. Asimismo, se clarifican cuestiones nomenclaturales, se realizan tipificaciones, se aportan datos etnobotánicos y se actualiza la distribución de las especies especialmente para la Argentina y en algún caso para el Paraguay.

\section{Materiales y Métodos}

Se analizó material perteneciente a los herbarios BA, BAB, BM, BR, C, CTES, F, FCQ, G, GH, GOET, JUA, K, MO, NY, P, PACA, S, SF,
SI y US (Thiers, 2018) y se realizaron viajes de campo (ver material examinado en cada especie). El material tipo fue examinado a través de las imágenes disponibles en JSTOR (https://plants. jstor.org/), en el sitio web del herbario PACA (http://www.anchietano.unisinos.br/index1.htm), o en el caso del holotipo de Ctenanthe casupoides Petersen var. subtropicalis Hauman en el herbario donde se halla depositado (BA). Siempre que fue posible, se indicó a continuación de las siglas del herbario el código de barras en los materiales tipo, caso contrario se indicó el número del herbario (seguido de un guión). Se cita todo el material examinado cuando la especie está representada en una sola provincia y cuando se halla en más de una, solo se agrega un ejemplar para cada una de estas.

Se procedió a la designación de un lectotipo, cuando en el protólogo no se especifica la institución de depósito del ejemplar tipo, siguiendo a McNeill et al. (2012) y a las recomendaciones citadas en McNeill (2014).

Se siguió a Andersson (1976) para describir la morfología de la inflorescencia en la clave dicotómica.

\section{Resultados}

En este trabajo se reconocen seis géneros y siete especies de Marantaceae para la Argentina: Ctenanthe muelleri Petersen, Goeppertia eichleri (Petersen) Borchs. \& S. Suárez, Maranta sobolifera L. Andersson, Saranthe eichleri Petersen, Stromanthe boliviana K. Schum., Thalia geniculata L. y T. multiflora Horkel ex Körn. De dichas especies, dos, Ctenanthe muelleri y Saranthe eichleri, se registran por primera vez para la Argentina, y C. muelleri se cita además por primera vez para el Paraguay. Se sinonimiza a Ctenanthe casupoides var. subtropicalis bajo S. eichleri. Se designan lectotipos para Calathea eichleri Petersen (actualmente G. eichleri), C. macrostachya Griseb. (actualmente Thalia multiflora), S. eichleri y T. geniculata. Para cada una de las especies, de ser posible, se brinda información respecto a la iconografía, nombres vulgares, observaciones, etnobotánica, distribución geográfica y hábitat, y se cita el material examinado. 
1. Inflorescencias estrobiliformes con las espatas de disposición helicoidal, densamente agrupadas e imbricadas; espatas dimorfas (las inferiores ovadas de ápice redondeado a agudo y las superiores lanceoladas de ápice acuminado a triangular-lanceolado), persistentes; ovarios con tres lóculos fértiles.

Goeppertia eichleri

1 '. Inflorescencias con las espatas de disposición dística o en paniculodios laxos o densos, imbricadas o no; espatas monomorfas, caducas o no; ovarios con un lóculo fértil, los otros dos vacíos y completamente

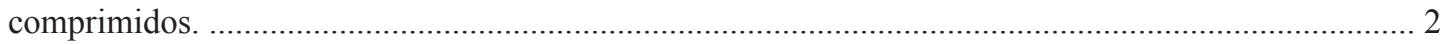

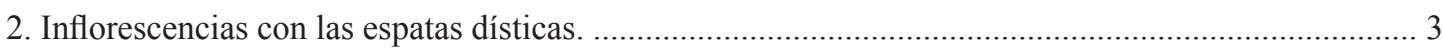

3. Espata con 3(-5) pares de flores; con un profilo acompañando al pedicelo de cada par de flores y un par de bractéolas acompañando a cada flor; espata con el ápice redondeado y margen liso, usualmente persistentes; flores blancas con los ápices violáceos.

Ctenanthe muelleri

3'. Espata y profilo con un par de flores; sin bractéolas; espata con el ápice agudo y el margen superior ciliado, usualmente caducas; flores blancas con el centro amarillo. Saranthe eichleri

2 '. Inflorescencias con las espatas dispuestas en paniculodios laxos o densos. 4

4. Estaminodio externo 1; espatas cartáceas y fibrosas, caducas. 5

5. Inflorescencias difusas con los entrenudos generalmente mayores a $1 \mathrm{~cm}$ de largo.

Thalia geniculata

5'. Inflorescencias congestas, espiciformes, con los entrenudos generalmente menores a $5 \mathrm{~mm}$ de largo.

Thalia multiflora

4'. Estaminodios externos 2; espatas herbáceas no caducas. 6

6. Ovario y fruto de superficie tuberculada; 5-7 florescencias por raquis; cara abaxial de la hoja densamente híspido a los costados del nervio medio; tubo corolino corto y recto.

Stromanthe boliviana

6'. Ovario y fruto de superficie lisa; 2-3 florescencias por raquis; cara abaxial de la hoja glabra a glabrescente a los costados del nervio medio; tubo corolino largo y giboso; se distribuye en el Litoral argentino.

Maranta sobolifera

\section{Tratamiento taxonómico}

1. Ctenanthe muelleri Petersen. Fl. Bras. 3(3): 161. 1890. Tipo. Brasil. Rio Grande do Sul, "Schwanschneis p.[rope] Novo Hamburgo in silva primavera", 25-V-1949, Rambo s.n. (neotipo PACA-41704 [foto]!, designado por Yoshida-Arns \& Mayo, 2003: 14).

\section{Iconografia. Figs. 1 y 2.}

Nombre vulgar. "Peguao" (Keller et al. 3313, CTES). Es una expresión guaraní, contracción de "yvype-gua-o" (hojas de las zonas bajas) y que se aplica a todas las especies de la familia.

Etnobotánica. Los guaraníes emplean sus láminas foliares para confeccionar vasos cónicos ocasionales para beber agua de las vertientes o cursos de agua donde la planta crece. También, las hojas son empleadas como envoltorio para la cocción de larvas de escarabajos y de alimentos a base de choclo o granos inmaduros de maíz (Keller, 2008).

Distribución geográfica y hábitat. Se distribuye en el sudeste y sur del Brasil (Braga \& Saka, 2015). En este trabajo se cita por primera vez para el sur del Paraguay (Caazapá) y para el noreste de la Argentina (Misiones), en donde habita en el sotobosque del interior de la selva, en sitios húmedos y umbríos, al lado de arroyos, en bordes de caminos o en picadas. También, se la puede encontrar creciendo sobre suelo rocoso, entre los $150-750 \mathrm{~m} \mathrm{~s} . \mathrm{m}$. 
Bol. Soc. Argent. Bot. 53 (3) 2018

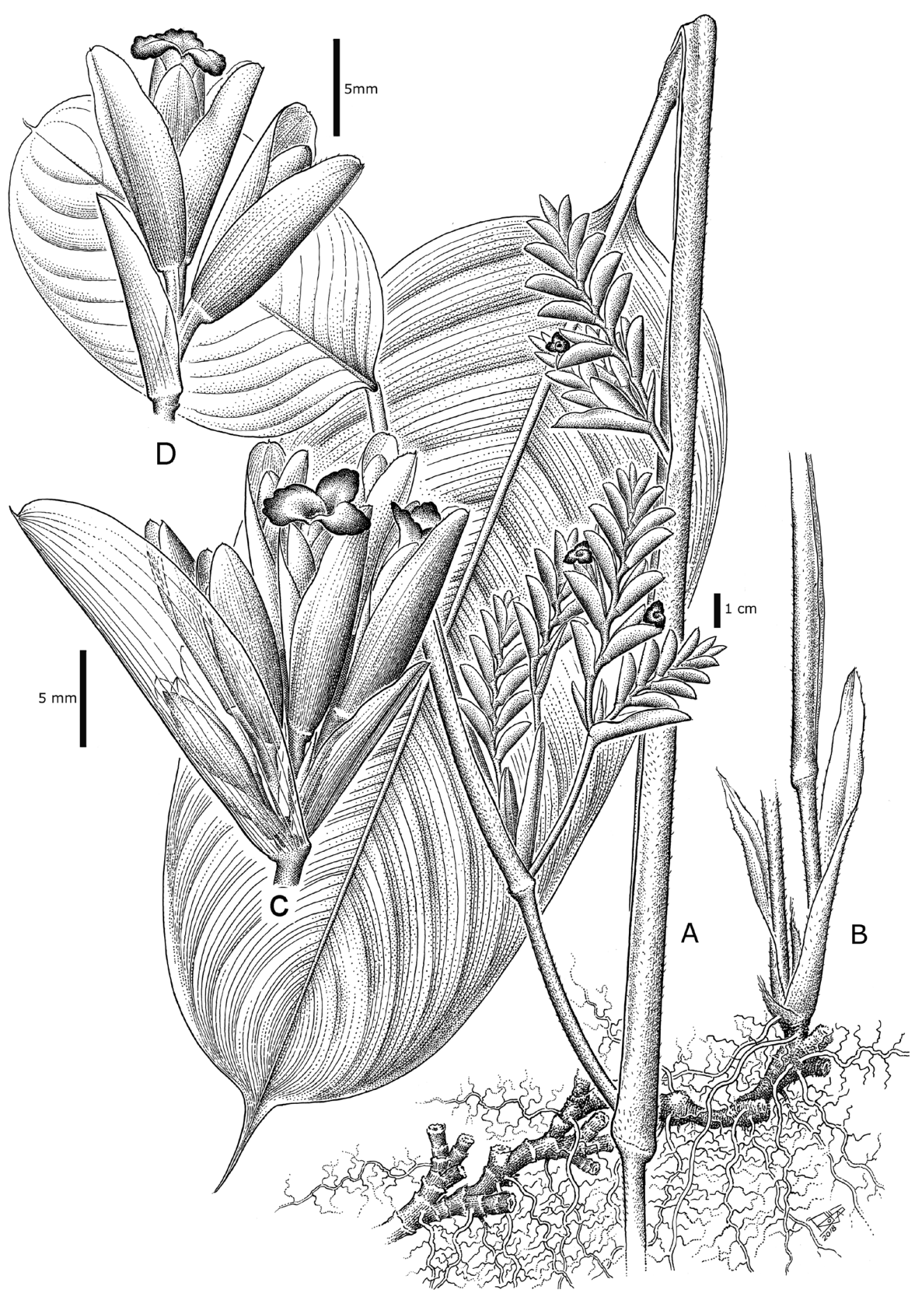

Fig. 1. Ctenanthe muelleri. A: Hábito. B: Rizoma y porción basal de la planta. C: Inflorescencia (la espata se dibujó en transparencia para dejar ver la estructura interna). D: Detalle de un par de flores acompañado por un profilo en el pedicelo y con bractéolas acompañando a cada flor. A, C y D: Guaglianone et al. 2657 (SI); B: Hunziker et al. 10851 (SI). Dibujos: F. Rojas. 
C. A. Zanotti et al. - Sinopsis y novedades taxonómicas de la familia Marantaceae
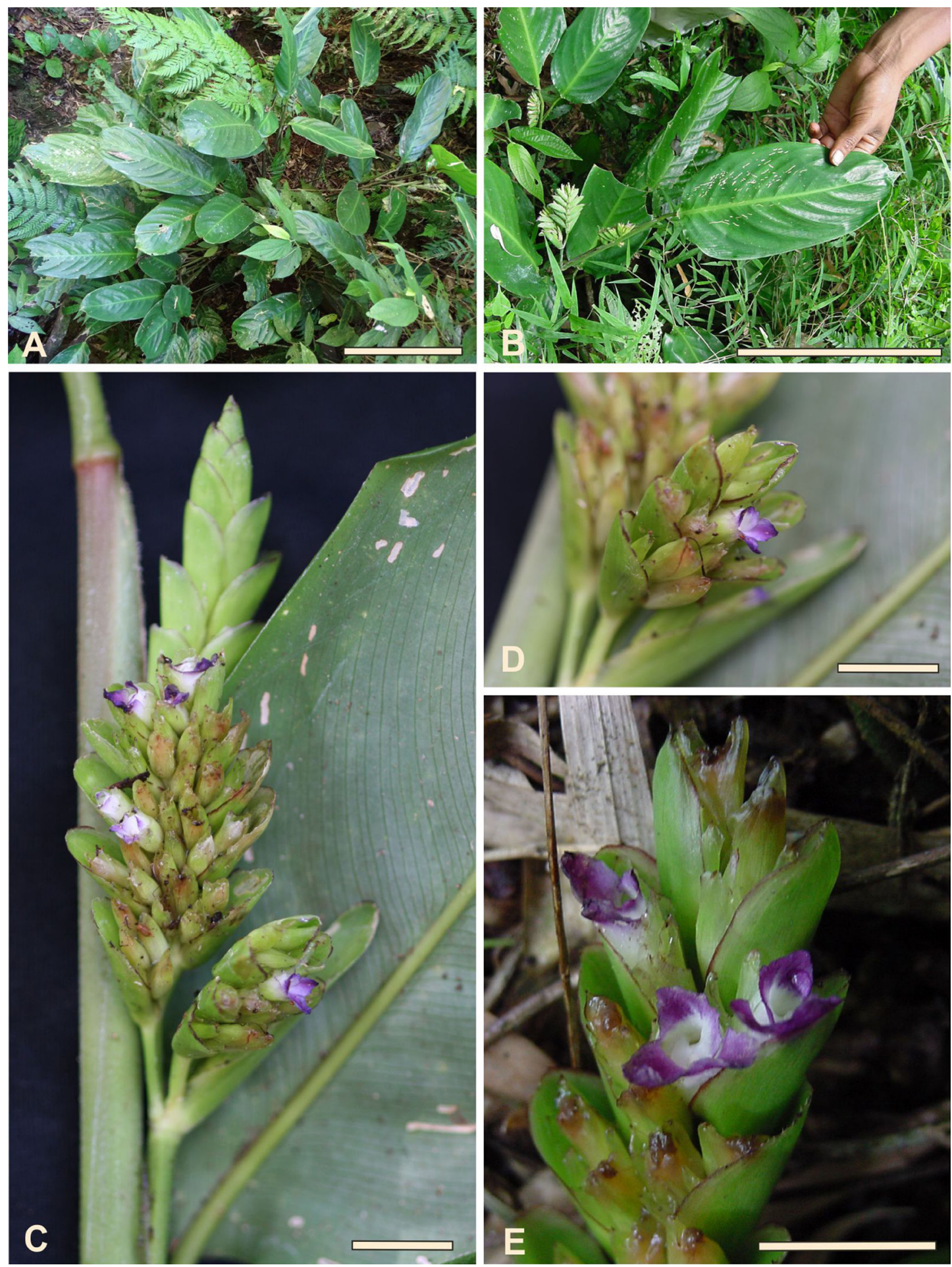

Fig. 2. Ctenanthe muelleri. A: Hábito. B: Hojas. C-D: Inflorescencia. E: Flores. Escalas=A-B: $30 \mathrm{~cm}$; C-D: $2 \mathrm{~cm}$; E: $3 \mathrm{~cm}$. Fotos: A- B, E: H. Keller; C, D: M. Belgrano. 
Material estudiado. ARGENTINA. Prov. Misiones: Dpto. Cainguás, $3 \mathrm{~km}$ de Aristóbulo del Valle, hacia Jardín América, 8-XII-1983, Hunziker et al. 10851, 10867 (SI); predio de la Universidad Nacional de La Plata [Aristóbulo del Valle], camino al bosque detrás de la comunidad indígena, 210 m, 24-IX-1997, Zuloaga \& Morrone 6504 (SI); Ruta Provincial 220, $3,5 \mathrm{~km}$ de Salto Encantado camino a Garuhapé, 365 m, 19-X-1996, Morrone et al. 1577 (SI). Dpto. Eldorado, Parque Natural Municipal Saltos Küpers, Arroyo Patycuá, 5-I-2004, Keller 2636 (CTES). Dpto. General Manuel Belgrano, Reserva de Vida Silvestre Urugua-í, sendero "Los Pozones", 300 m,18-II-2005, Belgrano et al. 364 (SI). Dpto. Guarani, Predio Guaraní, picada hacia Arroyo Paraíso, 480 m, 5-V1999, Deginani et al. 1016 (SI); camino de El Soberbio a Mesa Redonda, cruce con desvío hacia Colonia Pepirí, 390 m, 1-III-2000, Deginani et al. 1576 (SI); sendero en sotobosque bordeando arroyo, $180 \mathrm{~m}, 12-$ XI-2000, Múlgura et al. 2599 (SI); Predio Guaraní, Tramo I, 5-I-2004, Tressens et al. 4707 (CTES); ídem, Sendero Chachi, 11-I-2006, Keller et al. 3313 (CTES). Dpto. Iguazú, Parque Nacional Iguazú, 15-XI-1976, Guaglianone et al. 39 (SI); idem, Sendero Macuco, 155 m, 1-XII-1993, Vanni et al. 3084 (CTES, SI); Río Uruguaí, curso medio, Campamento Yacu-Poi, 3-XI1949, Perrone s.n. (BA-54171). Dpto. San Ignacio, Ñacan Guazú, I-1918, Hauman s.n. (BA-17203). Dpto. San Pedro, Parque Provincial Moconá, 14-XI1995, Guaglianone et al. 2857 (SI); Ruta Nacional 14, $32 \mathrm{~km}$ de Bernardo de Irigoyen camino a Tobuna, 750 m, 17-X-1996, Morrone et al. 1520 (SI); Parque Provincial Moconá, picada a La Gruta, 210 m, 13IV-1996, Zuloaga et al 5464 (SI); cruzando el puente sobre el Yabotí hacia los obrajes, Ruta proyectada 102, 200 m, 9-V-1999, Deginani et al. 1216 (SI); Parque Provincial Piñalito, 5-III-2000, Deginani et al. 1685 (SI); Reserva de Biósfera Yabotí, Parque Provincial Esmeralda, sendero junto al arroyito de la "toma de agua", 550 m, 22-XI-2006, Belgrano et al. 584 (SI). PARAGUAY. Dpto. Caazapá, mun. Caazapá, cercanías del Arroyo Charará, XII-1988, Mereles 2031 (FCQ, SI). Sin departamento ni localidad indicados, 5-III-1928, Jörgensen 3897 (SI).

2. Goeppertia eichleri (Petersen) Borchs. \& S. Suárez. Syst. Bot. 37: 630. 2012. Calathea eichleri Petersen. Fl. Bras. 3(3): 108, tab. 20.
1890. $\equiv$ Phyllodes eichleri (Petersen) Kuntze. Revis. Gen. Pl. 2: 696. 1891. Tipo. Brasil. Rio de Janeiro, Gavea, 6-X-1872, Glaziou 6456 (lectotipo, aquí designado P 00604258 [foto]!; isolectotipos C 10014428 [foto]!, F 0BN009817 [foto]!, K 000586804 [foto]!, P 00604259 [foto]!, P 00604260 [foto]!,). Fig. 3, A-B.

Iconografía. Petersen, 1890: tab. 20, fig. II. Schumann, 1902: 79, fig. 13A. Vieira et al., 2012b: 211, prancha 1. A-C (sub Calathea eichleri).

\section{Nombre vulgar. "Peguao" (Keller, 2008).}

Observaciones nomenclaturales. En el protólogo de Calathea eichleri, Petersen (1890) cita como material original "Habitat in Brasilia ad Gaviam: Glaziou n. 6456". Es probable que el material que utilizó Petersen para describir a la especie haya provenido del herbario de Berlín, ya que la ilustración publicada en el protólogo (tab. 20) se asemeja a la foto de la Serie de Field Museum (F 0BN009817) proveniente del ejemplar de B, destruido en la Segunda Guerra Mundial (Robert Vogt, com. pers.).

La colección Glaziou 6456 se ha encontrado en los herbarios europeos C, K y P. Sin embargo, los únicos ejemplares en cuyos labelos se cita la localidad completa brindada en el protólogo son los depositados en P. Se designa como lectotipo al ejemplar P 00604258, por ajustarse adecuadamente al protólogo, presentar localidad completa y la etiqueta original con la letra manuscrita del colector.

Distribución geográfica y hábitat. Según Braga \& Saka (2015) esta especie es endémica del centrooeste y sur del Brasil, habitando en el interior de selvas en lugares húmedos y umbríos, aunque a veces también en sitios pantanosos (Vieira et al., 2012b; Braga \& Saka, 2015). Sin embargo, es reconocida para la flora del Paraguay por Zuloaga et al. (2008), criterio que se sigue en este trabajo. En la Argentina, se la encuentra solo en la provincia de Misiones, en donde habita en bordes de lagunas, barranco de arroyos, montes de Araucaria sp., bañados y frecuentemente en el sotobosque del interior de selvas, entre los 200-700 m s. m.

Material estudiado. ARGENTINA. Prov. Misiones: Dpto. Eldorado, $\mathrm{km} \mathrm{24,} \mathrm{9-XII-}$ 

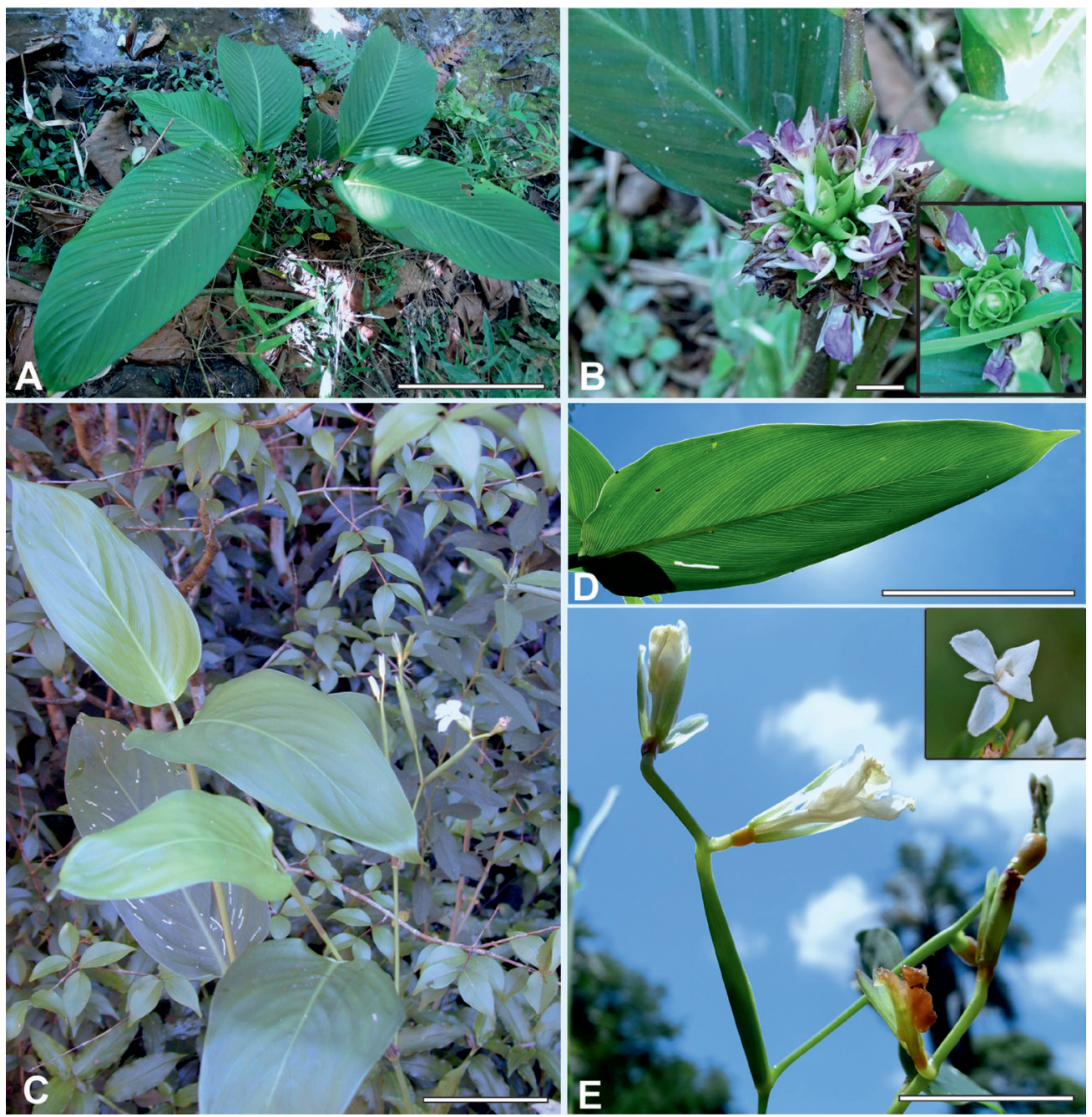

Fig. 3. A-B: Goeppertia eichleri. A: Hábito. B: Inflorescencia. C-D: Maranta sobolifera. C: Hábito. D: Lámina foliar. E: Inflorescencia y detalle de una flor. Escalas= A: $30 \mathrm{~cm}$; B: $2 \mathrm{~cm}$; C-D: $4 \mathrm{~cm}$; E: $2 \mathrm{~cm}$. Fotos: A-B, D-E: H. Keller; E: detalle de la flor: J. Pensiero; C: S. Denham.

1943, Burkart 14636 (SI). Dpto. General Manuel Belgrano, Bernardo de Irigoyen, Ruta 17, cruce con la Ruta 14, 19-II-1992, Tur \& Guaglianone 2009 (SI); Juan Manuel de Rosas, Salto Andresito, Arroyo Gramado, Ruta 101, 31-I-1983, Guaglianone et al. 1175 (SI); $6 \mathrm{~km}$ al S de Bernardo de Irigoyen, Arroyo Macuco, 4-I-1970, Maruñak 105 (SI); Reserva Estricta de San Antonio, 15-XII-1997, Múlgura et al. 1886 (SI); ídem, Cascada Andresito, 23-II-1971, Burkart 28280 (SI); Ruta Nacional 101, 8 km al $\mathrm{N}$ de San Antonio, INTA, $480 \mathrm{~m}, 21-\mathrm{XI}$ -
1995, Guaglianone et al. 2988 (SI); sobre Ruta Nacional 101, alrededores de Deseado, 19-XII1997, Ahumada et al. 7658 (JUA). Dpto. Guaraní, predio de "Moconá Naturaleza y Aventura", sendero y alrededores del Salto Horacio Foerster, Arroyo Oveja Negra, 200 m, 28-II-2000, Deginani et al. 1544 (SI); Fracrán, 19/23-II-1924, Hauman s.n. (BA). Dpto. Iguazú, Parque Nacional Iguazú, cataratas, Palmital Chico, 25-X-1991, Hunziker et al. 11926 (SI); Parque Nacional Iguazú, pasarelas inferiores de cataratas, $270 \mathrm{~m}, 12-\mathrm{X}$ 1996, Morrone et al. 1215 (SI); Parque Nacional 
Iguazú, Arroyo Central, XII-1969, Ravenna s.n. (BA-80237); Iguazú, $20 \mathrm{~km} \mathrm{E} \mathrm{de} \mathrm{Wanda} \mathrm{a} \mathrm{J.} \mathrm{J.}$ Lanusse, 24-I-1973, Schinini 6031 (SI); cerca del Iguazú, I-1918, Hauman s.n. (BA-17172). Dpto. Libertador General San Martín, Salto Encantado, Parque Provincial, 26-II-1995, Zuloaga et al. 4950 (SI); ídem, 11-XII-1997, Múlgura et al. 1768 (SI). Dpto. San Pedro, Eskuche 12-93 (SI); Parque Provincial Cruce Caballero, 690 m, 15-IV-1996, Zuloaga et al 5528 (SI); Parque Provincial Piñalito, 5-III-2000, Deginani et al. 1683 (SI); Parque Provincial Moconá, 14-XI-1995, Guaglianone et al. 2855 (SI).

3. Maranta sobolifera L. Andersson. Nordic J. Bot. 6: 742. 1986. Tipo. Brasil. Rio Grande do Sul. "Ex colonia Santo Angelo, in dumetis umbrosis", 18-I-1893, Lindman A-993 (holotipo S R-3422 [foto]!, isotipos S 05-6297[ foto]!, S 05-6298 [foto]!, S 05-6299 [foto]!). Fig. 3, C-E.

Iconografía. Andersson, 1986: 734 (fig. 2D), 737 (fig. 4D), 738 (fig. 5C), 744 (fig. 9A-B); Vieira et al., 2012b: 223, prancha 4D.

Nombres vulgares. "Achira blanca" (Montes 735, BA), "Anyiyiba" (Keller \& Romero, 2006), “Caité" (Montes 738, BA), "Peguá o Miri” (Keller 693, CTES).

Etnobotánica. En las colonias rurales del entorno de la Reserva de Biosfera Yabotí de la provincia de Misiones, los rizomas se emplean en un tratamiento para prevenir las caries (Keller \& Romero, 2006). Se la considera una maleza de difícil control en los yerbatales (i.e., Ilex paraguariensis A. St.-Hil.) de la provincia, en virtud de su propagación mediante rizomas. Entre los guaraníes, la especie se aplica para tratar afecciones tales como cefalalgias, otitis, mamitis, afecciones cardíacas, fiebre estomacal y micción sanguinolenta. Las hojas son empleadas como envoltorios para la cocción de alimentos. Los niños guaraníes elaboran un silbato con las vainas foliares (Keller, 2008).

Distribución geográfica y hábitat. Se distribuye en la Argentina, el Paraguay y en el sudoeste y sur del Brasil, en donde habita en ambientes con agua, soleados, en bordes de bosques en galería (Andersson, 1986; Vieira et al., 2012b; Braga \& Saka, 2015). En la Argentina, se distribuye en la región del Litoral, en donde habita variados hábitats desde interior de sotobosques de selvas en galerías, montes, bordes de selvas y de caminos, orillas de bañados, en áreas desmontadas y modificadas, generalmente en ambientes húmedos y sombríos, entre los $120750 \mathrm{~m} \mathrm{~s}$. m.

Material estudiado. ARGENTINA. Prov. Chaco: Dpto. Bermejo, alrededores de Puerto Las Palmas, 26-XI-1990, Fortunato et al. 1731 (BAB, SI). Prov. Corrientes: Dpto. Santo Tomé, Gobernador Virasoro, Establecimiento Timbauva, a ca. $9 \mathrm{~km}$ Ruta 14, a 22 km del casco y $13 \mathrm{~km} \mathrm{~N}$ del Arroyo Guaraní, 22-I1976, Romanczuk et al. 284 (SI). Prov. Formosa: Dpto. Pirané, $20 \mathrm{~km}$ al W de Pirané, Ruta 81, 13-I1980, Guaglianone et al. 649 (SI). Prov. Misiones: Dpto. San Pedro, Paraje Paraíso, aldea aborigen Guavirá Poty, 3-IV-2001, Keller 693 (CTES, SI). Prov. Santa Fe: Dpto. General Obligado, $5 \mathrm{~km}$ al E de Florencia, 10-XII-1986, Pensiero \& Vegetti 2675 (SI).

4. Saranthe eichleri Petersen. Fl. Bras. 3(3): 166. 1890. Tipo. Brasil. Rio de Janeiro, Floresta do Tijuca, 27-II-1870, Glaziou 4252 (lectotipo, aquí designado, C 10014469 [foto]!; isolectotipos C 10014467 [foto]!, C 10014468 [foto]!, P 00690015 [foto]!, P 00690016 [foto]!, P 00690017 [foto]!, F 0BN009847 [foto]!).

$=$ Ctenanthe casupoides Petersen var. subtropicalis Hauman. Anales Mus. Nac. Buenos Aires 29: 441. 1917. Tipo. Argentina. Misiones, Niederlein s.n. (holotipo BA-17201!), syn. nov. Fig. 4.

Iconografia. Figs. 4 (sub C. casupoides var. subtropicalis), 5 y 6.

Nombres vulgares. "Caá-te, Caité" (Glaziou 4252, P 00690015), "Caité” (Niederlein s.n., BA17201). La expresión "caité", que se aplica a la especie entre grupos criollos de Misiones, proviene del tupí-guaraní "ka'a-ete" (el vegetal genuino). En la mitología de estos grupos criollos, el reino vegetal actual, tuvo su origen con posterioridad al diluvio que acabó con la vida en la tierra, siendo frecuente la consideración de que ciertas especies 
C. A. Zanotti et al. - Sinopsis y novedades taxonómicas de la familia Marantaceae

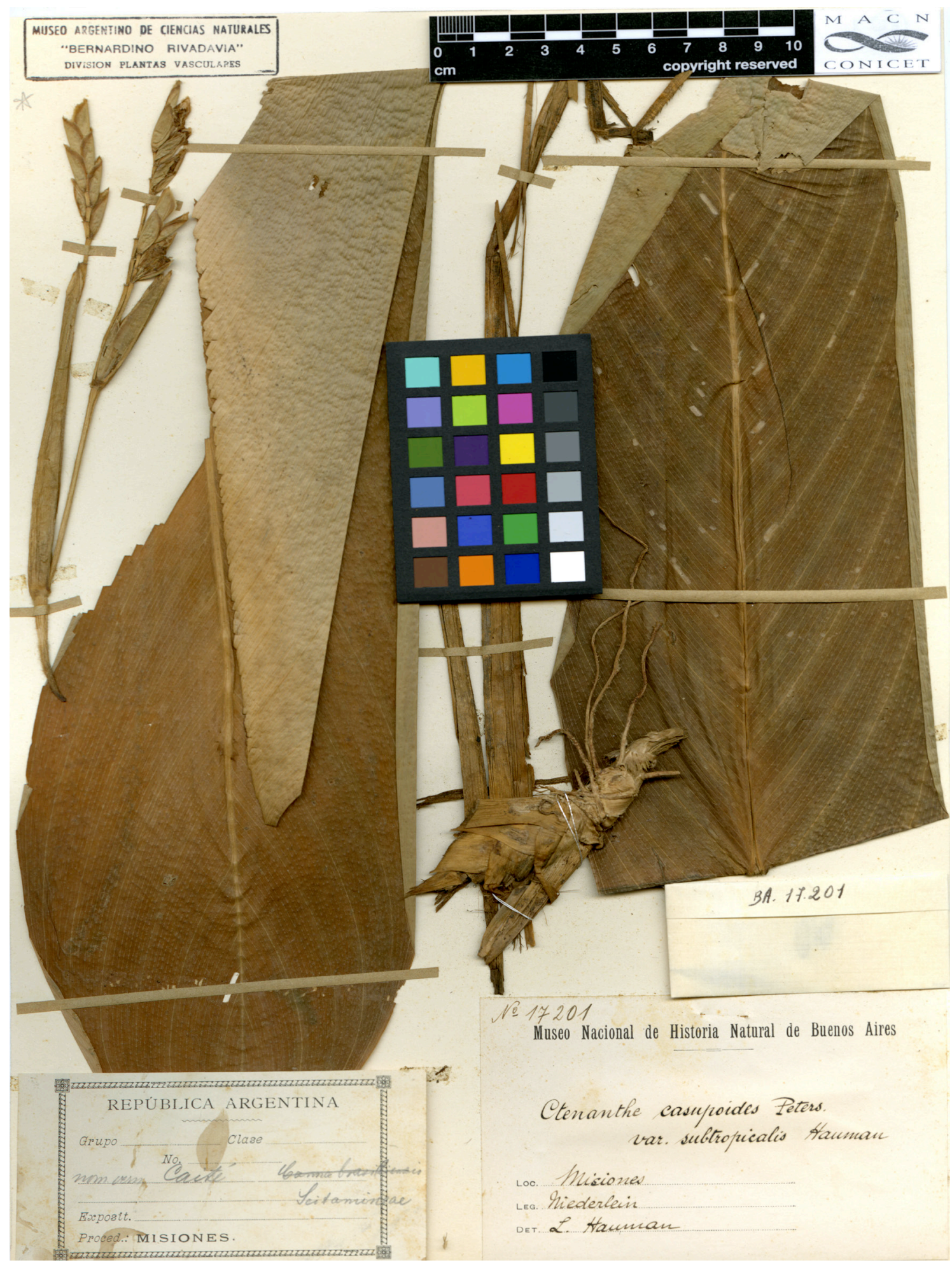

Fig. 4. Holotipo de Ctenanthe casupoides var. subtropicalis depositado en BA. 
Bol. Soc. Argent. Bot. 53 (3) 2018

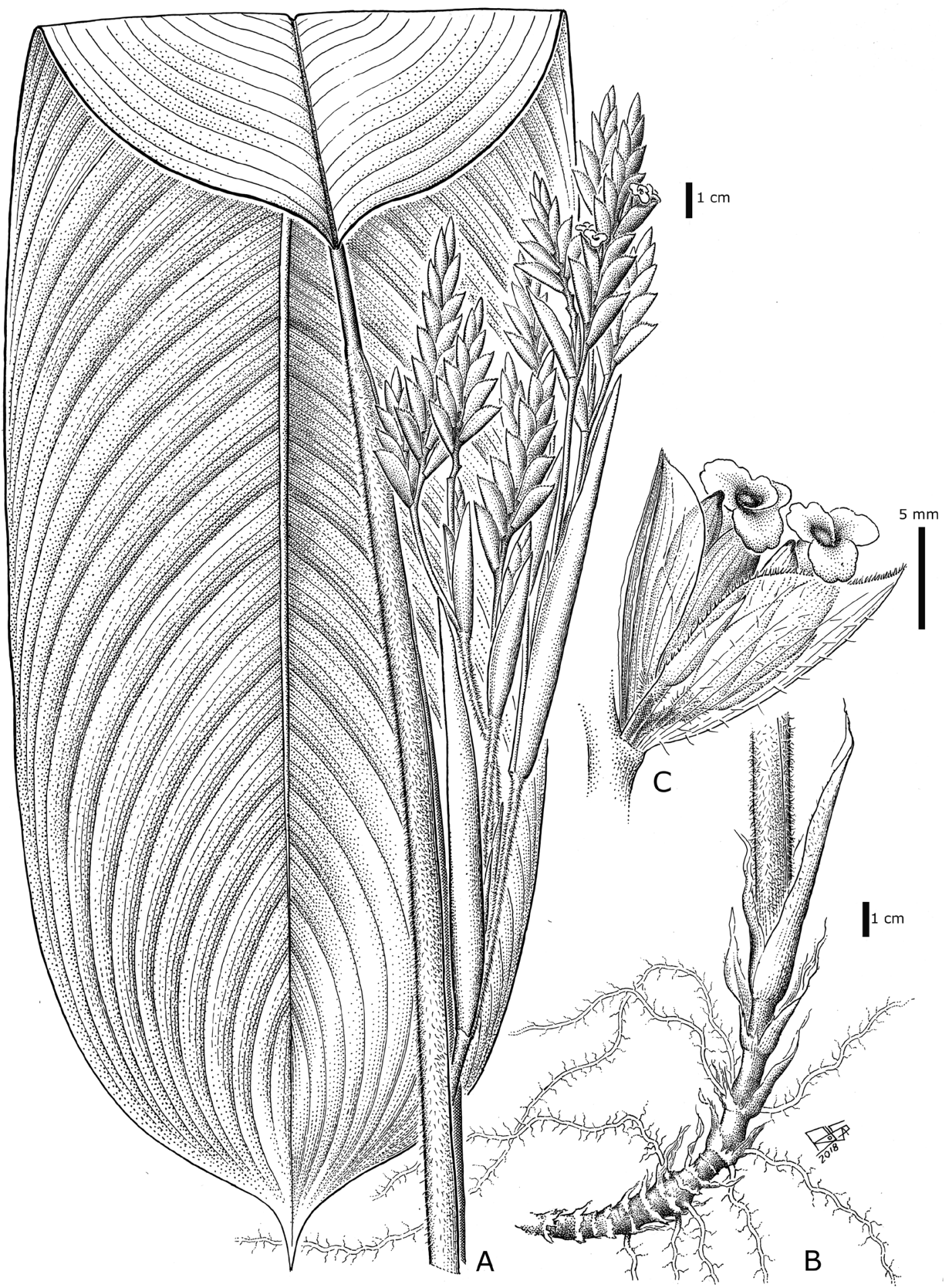

Fig. 5. Saranthe eichleri. A: Hoja e inflorescencia. B: Rizoma. C: Espata y profilo con un par de flores. Escalas= A-B: 1 cm; C: 5 mm. A, C: Keller \& Rojas 13531 (CTES); B: Fiebrig 5774 (SI). Dibujos: F. Rojas. 
C. A. Zanotti et al. - Sinopsis y novedades taxonómicas de la familia Marantaceae

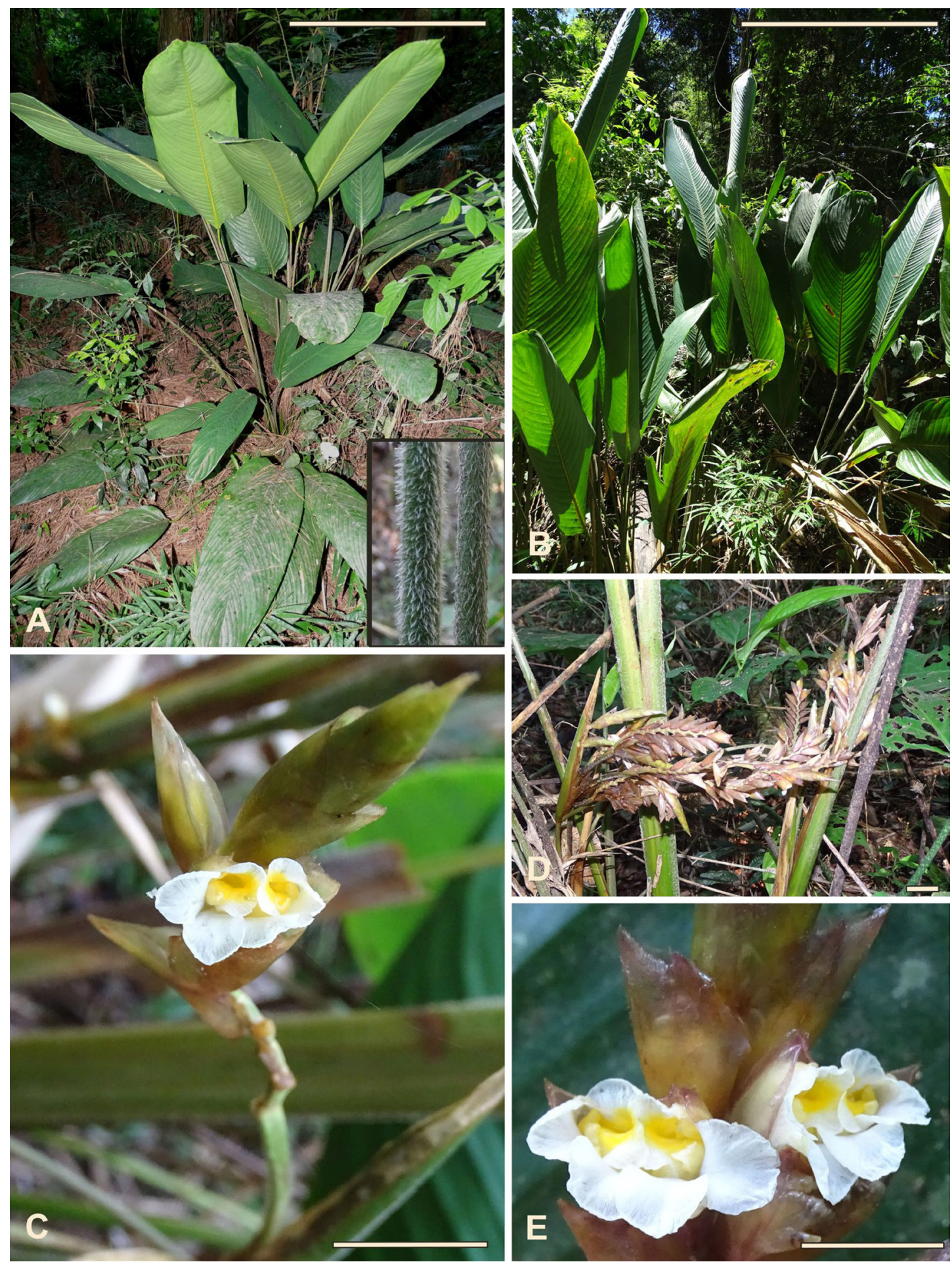

Fig. 6. Saranthe eichleri. A: Hábito. B: Hojas. C: Detalle de inflorescencia. D: Inflorescencia. E: Flores. Escalas= A-B: $45 \mathrm{~cm}$; C-D: $1,5 \mathrm{~cm}$; E: $1 \mathrm{~cm}$. Fotos: H. Keller. 
palustres o higrófilas han sido las predecesoras de la diversidad vegetal. En virtud de ello, tales plantas son denominadas con sufijos que indican su condición de "genuinas" o "primigenias" (Keller, 2013).

Observaciones nomenclaturales. En el protólogo de Saranthe eichleri, Petersen (1890) cita dos colecciones originales: "Habitat in Brasiliae prov. Rio de janeiro ad Tijuca: Glaziou n. 4252" e "in prov. S. Paulo, Serra de Caracol [Caraeve] in silva: Mosén n. 1716". La colección Mosén 1716 solo se halló en el herbario S (S 16-47964), mientras que el ejemplar Glaziou 4252 presenta seis pliegos distribuidos en los herbarios C y P. Se considera la colección de Glaziou 4252 más adecuada para la tipificación del nombre de la especie por estar representado en más de un herbario; no obstante, dentro de esta colección, los únicos ejemplares que presentan la localidad completa citada en el protólogo son los pliegos C 10014469 y P 00690015. Se designa como lectotipo al ejemplar C 10014469 ya que, además de coincidir morfológicamente con la descripción original y en el resto de datos brindados en el protólogo, Petersen trabajó en la Universidad de Copenhague (Stafleu \& Cowan, 1983) durante la elaboración de la monografía de Marantaceae para la Flora Brasiliensis (Yoshida-Arns \& Mayo, 2003) y lleva la firma de determinación del autor en 1889.

Hauman (1917) describe a Ctenanthe casupoides var. subtropicalis por la presencia de un par de flores por espata y la ausencia de bractéolas acompañando a las flores. Estas características, concuerdan con lo descripto para el género Saranthe Eichler, y por este motivo Yoshida-Arns \& Mayo (2003) la excluyen del género Ctenanthe Eichler. Del análisis del material tipo depositado en BA, se confirma que este espécimen corresponde al género Saranthe, en concordancia con lo expuesto por Yoshida-Arns \& Mayo (2003), y que pertenece a $S$. eichleri, ya que presenta la espata con el ápice agudo y con el margen ciliado característico de este taxón (Vieira et al., 2012b; Funez et al., 2016). Por estos motivos se sinonimiza a $C$. casupoides var. subtropicalis bajo Saranthe eichleri.

Distribución geográfica y hábitat. Esta especie se distribuye desde Perú, Bolivia, Paraguay y el norte y noreste del Brasil hasta el sudeste y sur de este último país, en donde habita principalmente en lugares húmedos y sombríos, próximas a cuerpos de agua (Vieira et al., 2012b; Braga \& Saka, 2015). En la Argentina, nueva cita en este trabajo, solo crece en la provincia de Misiones y se la encuentra en el sotobosque del interior de la selva con abundancia de Euterpe edulis Mart. (Arecaceae), sobre suelos lateríticos profundos, entre los 300-400 m s. m.

Material estudiado. ARGENTINA. Prov. Misiones: Dpto. Iguazú, Reserva San Jorge, 337 m, 12-XII-2016, Keller \& Rojas 13531 (CTES, SI); Reserva Forestal Parque Nacional Iguazú, a $6 \mathrm{~km}$ SE de Puerto Iguazú, ca. $1 \mathrm{~km}$ de Ruta Nacional 12, 31-I-1976, Romanczuk et al. 605 (SI).

5. Stromanthe boliviana K. Schum. Pflanzenr. (Heft 11) 4: 151. 1902. Tipo: Bolivia. La Paz, Yungas, 1890, Bang 513 [543 en el protólogo] (lectotipo NY 00320424 [foto]!, designado por Zanotti et al., 2017: 190; isolectotipos BM 000923858 [foto]!, GH 00030740 [foto]!, G 00098950 [foto]!, K 000586916 [foto]!, MO 2309167 [foto]!, NY 00320423 [foto]!, NY 00320425 [foto]!, US 00093219 [foto]!, US 00733356 [foto]!). Fig. 7, A-B.

Iconografia. Zanotti et al., 2017: 190, Fig. 1; 191, Fig. 2.

Nombre vulgar. "Cañuela” (Schreiter 3613, SI).

Distribución geográfica y hábitat. Se distribuye en las Yungas de Bolivia y en el noroeste de la Argentina en las provincias de Jujuy y Salta, en donde crece al pie de las montañas, en los bordes de las rutas, entre los 300-1400 m s. m. (Zanotti et al., 2017).

Material estudiado. ARGENTINA. Prov. Jujuy: Dpto. Ledesma, Ruta Provincial 83, Parque Nacional Calilegua, $8 \mathrm{~km}$ del Río Agua Negra camino a San Francisco, 960 m, 20-II-1998, Morrone et al. 2817 (SI). Prov. Salta: Dpto. General José de San Martín, 20 km de Piquirenda camino a San Pedrito, $10 \mathrm{~km}$ del Charrito, Sierra de Tartagal, 25-XI-2001, Morrone et al. 4085 (SI). 
C. A. Zanotti et al. - Sinopsis y novedades taxonómicas de la familia Marantaceae
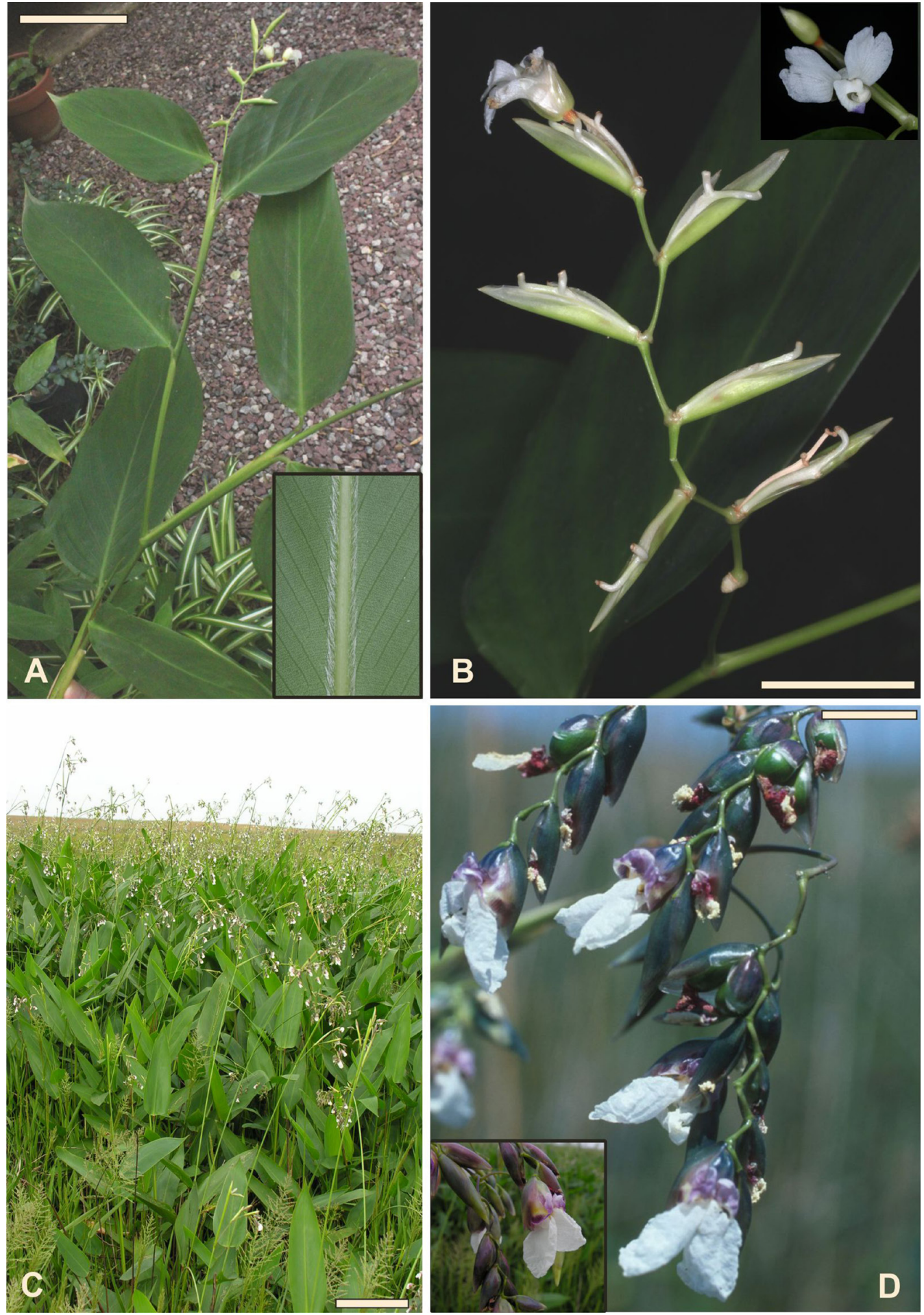

Fig. 7. A-B: Stromanthe boliviana. A: Hábito y detalle de la cara abaxial de la lámina foliar. B: Inflorescencia y detalle de una flor. C-D: Thalia geniculata. C: Hábito. D: Inflorescencia y detalle de una flor. Escalas= A: 5 cm; B: 2 cm; C: 30 cm; D: 2 cm. Fotos: A-B: C. Zanotti; C-D: J. Pensiero. 
6. Thalia geniculata L. Sp. Pl. 2: 1193. 1753. $\equiv$ Maranta geniculata (L.) Lam. Tabl. Encycl. 1: 9. 1791. 三Renealmia geniculata (L.). D. Dietr. Syn. Pl. 1: 14. 1839. Tipo: Plumier, Pl. Amer. 5, tab. CVIII, fig. 1. 1757 (lectotipo aquí designado). Fig. 7, C-D.

$=$ Thalia geniculata L. var. pubescens Körn. Bull. Soc. Imp. Naturalistes Moscou 35: 74. 1862. Tipo: México. "Ad ripas rivulorum prope Huichilingo", Kawinsky 857 (sintipo LE, no visto); "Guiana gallica" [Guayana Francesa], Poiteau s.n. (sintipo LE, no visto); "Brasilia, Sello" [Brasil, Sellow s.n.] (sintipo B, no visto).

= Thalia trichocalyx Gagnep. Bull. Soc. Bot. France 51: 180. 1904. Tipo: Guayana Francesa. Cayena, Richard s.n. (lectotipo P 00215223 [foto]!, designado por Andersson, 1981b: 55; isolectotipos $\mathrm{P}$ 00215221 [foto]!, P 00215222 [foto]!, P 00215234 [foto]!, P 00215235 [foto]!).

Iconografia. Plumier, 1757: tab. CVIII, fig. 1; Andersson, 1981 b: 49 (fig. 1), 50 (fig. 2); Vieira et al., 2012b: 229, prancha 5, fig. E.

Nombres vulgares: "Achira", "I-a'leena hikiatiwam'Pe" (Arenas \& Maranta 2715, BA), "Kiye'loq" (Maranta \& Arenas 163, BA), "Pairin" (Keller 10733, CTES), "pe'lak" (Arenas 2259, BA), "pe'lak 'poleo" (Filipov \& Arenas 41, BA), "pwe'lak" (Arenas 2007, BA), "Totora grande" (Schulz 57, SI).

Observación nomenclatural. En la descripción original de Thalia geniculata no se cita ningún material de referencia y, además, no hay ningún material original de esta especie en el herbario LINN donde se encuentran depositados los tipos de Linneo. Posiblemente, Linneo basó la descripción de la especie en una lámina del manuscrito de Plumier antes de ser publicado formalmente en 1757 (Andersson, 1981b). En la revisión del complejo de T. geniculata, Andersson (1981b) designó como lectotipo la ilustración "Plumier 1755: tab. 58, fig. 1". Sin embargo, esta ilustración ("tab. LVIII") corresponde a "Bignonia foliis conjugatis, cirrhofis, ternatis" (Bignoniaceae) que fue publicada en el fascículo 3 de la obra de Plumier en el año 1756 y no presenta ninguna indicación "fig. 1".

De acuerdo al Artículo 9.19(b) del Código Internacional de Nomenclatura (McNeill et al., 2012), este lectotipo debe ser reemplazado, ya que no coincide con la fecha ni con la referencia a la lámina del lectotipo designado por Andersson (1981b), y por lo tanto, se encuentra en serio conflicto con el protólogo. Debido a esto, se elige como un nuevo lectotipo la ilustración 108, figura 1 ("tab. CVIII. Fig. 1. Thalia"), del fascículo 5 de la publicación de Plumier en 1757.

Distribución geográfica y hábitat. Especie de amplia distribución en América, desde el sur del estado de Florida (Estados Unidos) hasta el centro de la Argentina; también se la encuentra en África, probablemente introducida. Esta especie habita frecuentemente en zonas pantanosas y abiertas (Andersson, 1981b). En la Argentina se halla en diversos hábitats como embalsados, esteros, borde de bosques marginales, zonas pantanosas, bordes de cursos de agua, charcas, cañadas, y es frecuente en zonas húmedas y completamente anegadas, entre los 0-400 m s. m.

Material estudiado. ARGENTINA. Prov. Buenos Aires: Dpto. San Pedro, Islote de Arnaldo, 30-XII-1943, Nicora 3580 (SI). Prov. Chaco: Dpto. $1^{\circ}$ de Mayo, Río Tragadero, 4-XI-1986, Charpin \& Eskuche 20106 (SI). Prov. Corrientes: Dpto. Itatí, Ruta Nacional 12, $60 \mathrm{~km}$ E de Itatí, Arrocera Rzepecki, 28-II-1977, Ahumada et al. 871 (CTES, SI). Distrito Federal: ciudad de Buenos Aires, Palermo, chacra municipal, 26-II-1902, Hicken 55 (SI-39634). Prov. Entre Ríos: Dpto. Islas del Ibicuy, Brazo Largo, Ruta Nacional 12 y Río Paraná Guazú, 10 m, 30-III-2005, Morrone et al. 5184 (SI). Prov. Formosa: Dpto. Patiño, Ruta Provincial 26 al S de paso Naitek, 12-I-1980, Guaglianone et al. 634 (SI). Prov. Salta: Dpto. Rivadavia, Alto de la Sierra, 31-I-1984, Arenas \& Maranta 2715 (BA). Prov. Santa Fe: Dpto. Garay, Ruta 82, antes de la Ruta 253, 18-II-1994, D’Angelo 1079 (SI). Prov. Tucumán: Dpto. Monteros, Laguna [probablemente Puesto La Laguna], 400 m, 16-I-1922, Venturi 1657 (BA, SI).

7. Thalia multiflora Horkel ex Körn. Bull. Soc. Imp. Naturalistes Moscou 35: 76. 1862. Tipo: Brasil. 1840, Sellow s.n. (sintipos B, no visto, BR 0000013331245 [foto]!, K 000586943 [foto]!, K 000586944 [foto]!, LE, no visto, US 00867554 [foto]!, W, no visto). Fig. 8, A-B. 
= Calathea macrostachya Griseb. Abh. Königl. Ges. Wiss. Göttingen 24: 335.1879 (= Symb. Fl. Argent: 335. 1879). $\equiv$ Phyllodes grisebachiana (Griseb.) Kuntze. Revis. Gen. Pl. 2: 696. 1891. Tipo: Argentina. Entre Ríos, depto. Concepción del Uruguay, "in einer Lagune”, 8-XI-1875, Lorentz s.n. [Flora Uruguensis 385] (lectotipo, aquí designado, GOET 007829 [foto]!; isolectotipos GOET 007830 [foto]!, GOET 007831[foto]!).

Iconografia. Petersen, 1890: tab. 38, fig. I.

Nombres vulgares. "Pairirí" (Keller 10740, CTES), "p(w)e'la'gel'ta" (Arenas 2072, BA).

Observaciones nomenclaturales. Körnicke (1862) en el protólogo de Thalia multiflora cita "Brasilia leg. Sello Herb. Berol., Vindob, et Hort, et. Acad Petrop.". Es probable que el material que estudió Körnicke para describir esta especie se encuentre depositado en LE, ya que en el año de la publicación original de la especie, el autor se encontraba trabajando en esta institución (Stafleu \& Cowan, 1979). Este ejemplar no pudo ser examinado, ni tampoco se examinaron los duplicados depositados en B (probablemente destruidos), ni en $\mathrm{W}$ citados en el protólogo. Sin embargo, se encontraron duplicados de la colección original de Sellow en BR, K y US.

Grisebach (1879) cita en el protólogo de Calathea macrostachya como material original "pr. Concepción del Uruguay, in lagunis" coleccionado por Lorentz. Se encontraron cinco pliegos de materiales originales de la colección de Lorentz provenientes de la localidad citada en el protólogo: dos pliegos Lorentz s.n. [Flora Uruguensis 487] (CORD 00005736, CORD 00005737) y tres pliegos Lorentz s.n. [Flora Uruguensis 385] (GOET 007829, GOET 007830, GOET 007831). Los materiales originales analizados por Grisebach para describir la especie son los depositados en GOET, dado que este botánico nunca visitó Argentina (Stafleu \& Cowan, 1976). Por esta razón, se designa como lectotipo al ejemplar GOET 007829 por ajustarse adecuadamente con la descripción morfológica, presentar una etiqueta original y llevar la inscripción "Calathea macrostachya sp. nov." de la letra manuscrita de Grisebach.
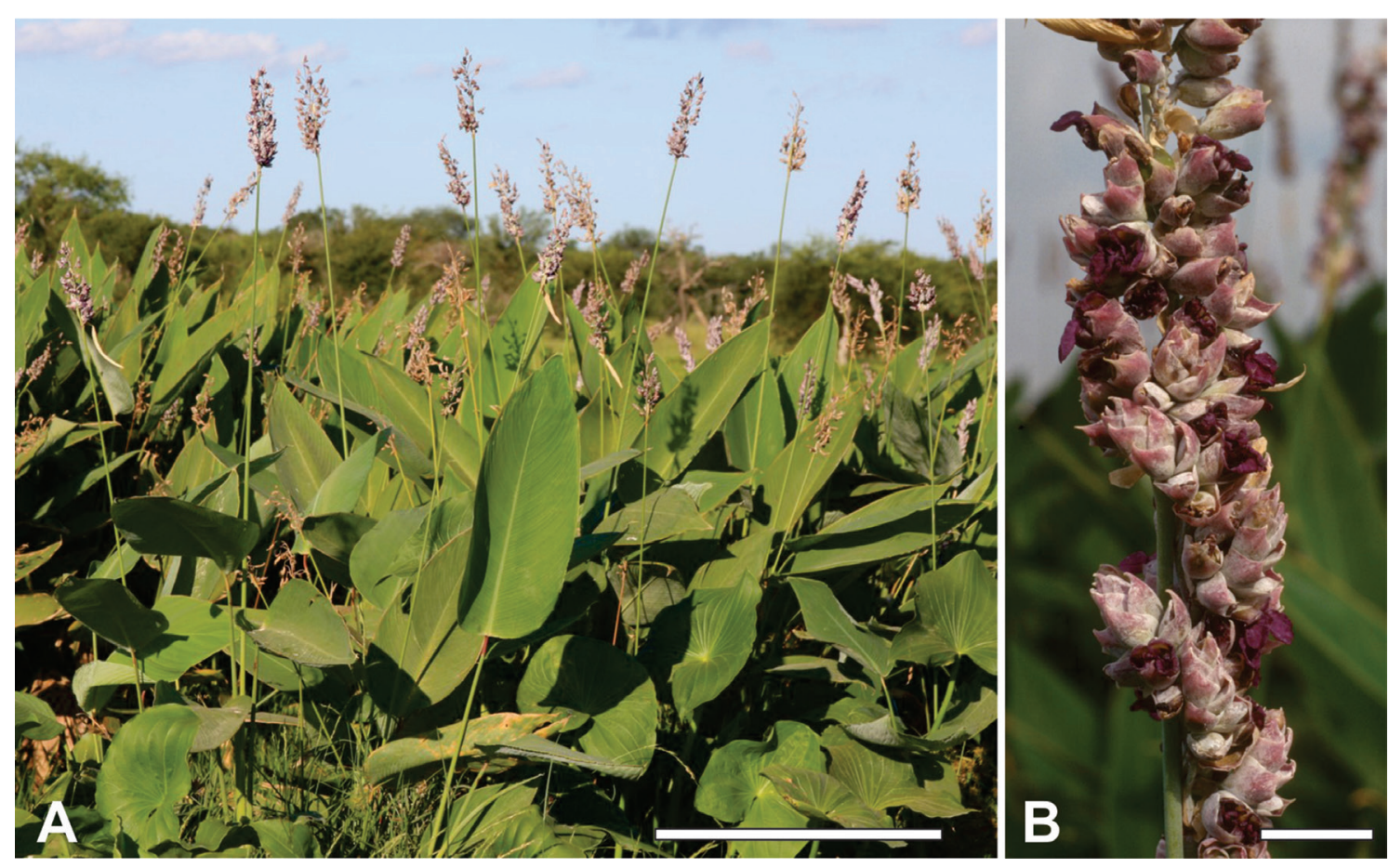

Fig. 8. Thalia multiflora. A: Hábito. B: Inflorescencia. Escalas= A: $30 \mathrm{~cm}$; B: $4 \mathrm{~cm}$. Fotos: J. Pensiero. 
Distribución geográfica y hábitat. Esta especie se distribuye en el sur de Brasil (Saka \& Braga, 2015), Paraguay, Uruguay y el noreste de la Argentina (Zuloaga, et al., 2008). En la Argentina crece en varios ambientes como zonas pantanosas, bañados, embalsados, orillas de cursos de agua, zanjas, cañadas, al costado de vías férreas, en campos de suelos arenosos y al borde de caminos, entre los 0-130 m s. m.

Material estudiado. ARGENTINA. Prov. Buenos Aires: Pdo. Tigre, camino a Benavídez, 10-III-1948, Lanfranchi 684 (SI). Prov. Chaco: Dpto. $1^{\circ}$ de Mayo, Colonia Benítez, V-1930, Schulz 56 (SI-39647). Prov. Corrientes: Dpto. Itatí, Ruta Nacional 12, $47 \mathrm{~km}$ E de Itatí, Estancia Santa Catalina, 26-II-1977, Ahumada et al. 759 (CTES, SI). Prov. Formosa: Dpto. Pilcomayo, Parque Nacional Pilcomayo, Laguna Blanca, 13-XII-1988, Guaglianone \& Múlgura 2190 (SI). Prov. Santa Fe: Dpto. San Javier, Ruta 1, cerca de San Javier, 30 m, 9-XI-1994, Pensiero 4839 (SF, SI).

\section{Especie excluida para la Flora Argentina}

Maranta divaricata Roscoe, Monandr. Pl. Scitam., tab. 27. 1828. $\equiv$ Maranta arundinacea L. var. divaricata (Roscoe) Hauman, Anales Mus. Nac. Buenos Aires 29: 441. 1917. Tipo: Probablemente en LIV, no encontrado.

El material original en el que se basó la descripción de esta especie provino de semillas enviadas por W. Harrison desde Brasil y cultivado en el invernadero de Arnold Harrison en 1825, a partir de la cual se realizó la ilustración que acompaña al protólogo.

Schumann (1902) reconoció la afinidad morfológica entre $M$. arundinacea L. y $M$. divaricata L. y las diferenció porque esta última presenta el ovario seríceo y por el tamaño relativamente menor de las hojas y de las flores. Posteriormente, Hauman (1917) subordinó a Maranta divaricata como una variedad de $M$. arundinacea en base a ejemplares provenientes de Chaco (Hauman s.n., BA-17197), Corrientes (Hauman s.n., BA-17198) y Misiones (i.e., Van de Venne s.n., BA-17199; Hauman s.n., BA, no visto; Rodríguez 346, BA-17200, SI), por presentar una gran variabilidad en cuanto a la pubescencia del ovario y a los tamaños relativos de las hojas y de la flor de las dos entidades reconocidas por Schumann (1902). Más recientemente, Andersson (1986), siguiendo el criterio de Schumann (1902), reestableció $M$. divaricata a nivel de especie y sostuvo que se puede diferenciar fácilmente de otras especies por la presencia de un ovario densamente seríceo y un denso indumento de pelos cortos, gruesos y adpresos en la cara abaxial del pulvínulo (ver fig. 4B en Andersson 1986) y en la parte proximal del nervio medio de la cara abaxial de la hoja.

De acuerdo a nuestro estudio, los ejemplares citados por Hauman (1917) para la Argentina, corresponden realmente a $M$. sobolifera, ya que presentan el ovario subglabro a irregularmente seríceo y la cara abaxial del pulvínulo y de las láminas glabras o raramente con algunos pelos dispersos (ver fig. 4D en Andersson 1986). Por esta razón, se excluye a $M$. divaricata de la Flora Argentina.

\section{Agradecimientos}

A Francisco Rojas (SI) por las ilustraciones de los nuevos registros. A Diego G. Gutiérrez y E. Celeste Alvarenga (BA); a Salete Marchioretto (PACA) por mandarnos las imágenes requeridas de los materiales tipo. A Gelina Pieszko (CTES). A J.M Braga y M. Saka por las consultas realizadas durante la elaboración del manuscrito, y a Robert Vogt, curador del herbario B. Al Lic. Gustavo Aparicio (Fundación Hábitat y Desarrollo) y la Ing. Liliana Rivero (Arauco S.A.) por posibilitar las campañas de recolección de Saranthe eichleri en Misiones. Al Ing. Lucas J. Rojas por el apoyo logístico durante las campañas de recolección. A J. Pensiero por permitirnos utilizar las fotografías de las dos especies de Thalia. La fotografía del material tipo de la Fig. 4 se reproduce con permiso del herbario BA (Museo Argentino de Ciencias Naturales). Un especial agradecimiento a Diego G. Gutiérrez y a dos revisores anónimos que contribuyeron en mejorar considerablemente el manuscrito.

\section{Bibliografía}

ANDERSSON, L. 1976. The synflorescence of the Marantaceae, Organization and descriptive terminology. Bot. Not. 129: 39-48. 


\section{A. Zanotti et al. - Sinopsis y novedades taxonómicas de la familia Marantaceae}

ANDERSSON, L. 1977. The genus Ischnosiphon (Marantaceae). Opera Bot. 43: 1-113.

ANDERSSON, L. 1981a. The Neotropical genera of Marantaceae. Circumscription and relationships. Nordic J. Bot. 1: 218-245.

ANDERSSON, L. 1981b. Revision of the Thalia geniculata complex (Marantaceae). Nordic J. Bot. 1: 48-56.

ANDERSSON, L. 1986. Revision of Maranta subgen. Maranta (Marantaceae). Nordic J. Bot. 6: 729-756.

ANDERSSON, L. 1998. Marantaceae. In: Kubitzki, K. (ed.), Monocotyledons: Alismatanae and Commelinanae (except Gramineae). The families and genera of vascular plants, Vol. IV, pp. 278293. Springer-Verlag, Berlin.

ANDERSSON, L. \& M. W. CHASE. 2001. Phylogeny and classification of Marantaceae. Bot. J. Linn. Soc. 135: 275-287.

BORCHSENIUS, F., L. S. S. SUÁREZ \& L. M. PRINCE. 2012. Molecular phylogeny and redefined generic limits of Calathea (Marantaceae). Syst. Bot. 37: 620-635.

BRAGA, J. M. A. 2005. Marantaceae: novidades taxonômicas e nomenclaturais III: tipificações sinonímias e uma nova combinação em Calathea. Acta Bot. Bras. 19: 763-768.

BRAGA, J. M. A. \& M. SAKA. 2015. Marantaceae. Lista de Espécies da Flora do Brasil. Jardim Botânico do Rio de Janeiro [on line]. Disponible en: $<$ http://floradobrasil.jbrj.gov.br/jabot/floradobrasil/ FB9341> [Acceso: 24 Noviembre 2017].

FUNEZ, L. A., G. HASSEMER \& R. TREVISAN. 2016. Rediscovery, typification, and conservation assessment of Saranthe ustulata (Marantaceae). Phytotaxa 255: 91-98.

GRISEBACH, A. H. R. 1879. Symbolae ad floram Argentinam. Zweite Bearbeitung argentinischer Pflanzen. Scitaminae. Abh. Köngl. Ges. Wiss. Göttingen 24: 335-336.

HAGBERG, M. \& R. ERIKSSON. 2011. New names in Monotagma (Marantaceae). Phytotaxa 20: 1-25.

HAUMAN, L. 1917. Notes Floristiques. Quelques Cryptogames, Gymnospermes et Monocotyledons de l'Argentine. Anales Mus. Nac. Hist. Nat. Buenos Aires 29: 391-443.

JUDD, W. S., C. S. CAMPBELL, E. A. KELLOG \& P. F. STEVENS. 1999. Plant systematics: a phylogenetic approach. Sinauer Associates, Massachussets.

KELLER, H. A. 2008. Etnobotánica de comunidades guaraníes de Misiones, Argentina. Valoración de la vegetación como fuente de recursos. Tesis de doctorado en Recursos Naturales, Facultad de Ciencias Agrarias, Universidad Nacional del Nordeste.
KELLER, H. A. 2013. Árboles y arbustos en mitos sobre el origen y el fin del mundo de los guaraníes meridionales: elucidación de algunas expresiones fitonímicas. Bonplandia 22: 149-158.

KELLER, H. A. \& H. F. ROMERO. 2006. Plantas medicinales utilizadas por campesinos del área de influencia de la Reserva de Biósfera Yabotí (Misiones, Argentina). Bonplandia 15: 125-141.

KÖRNICKE, F. 1862. Monographiae Marantearum Prodromus, pars altera. Bull. Soc. Imp. Naturalistes Moscou 35: 1-147.

KRESS, W. J. 1990. The phylogeny and classification of the Zingiberales. Ann. Missouri Bot. Gard. 77: 698-721.

KRESS, W. J. 1995. Phylogeny of the Zingiberanae: morphology and molecules. In: Rudall, P., P. J. Cribb, D. F. Cutler \& C. J. Humphries (eds.), Monocotyledons: systematics and evolution, pp. 443-460. Royal Botanical Gardens, Kew.

KRESS, W. J, L. M. PRINCE, W. J. HAHN \& E. A. ZIMMER. 2001. Unraveling the evolutionary radiation of the families of the Zingiberales using morphological and molecular evidence. Syst. Biol. 50: 926-944.

LEY, A. C \& R. CLAßEN-BOCKHOFF. 2009. Pollination syndromes in African Marantaceae. Ann. Bot. 104: 41-56.

MCNEILL, J. 2014. Holotype specimens and type citations: General issues. Taxon 63: 1112-1113.

MCNEILL, J., F. R. BARRIE, W. R. BUCK, V. DEMOULIN, W. GREUTER, D. L. HAWKSWORTH, P. S. HERENDEEN, S. KNAPP, K. MARHOLD, J. PRADO, W. F. PRUD'HOMME VAN REINE, G. F. SMITH, J. H. WIERSEMA \& N. J. TURLAND (eds.). 2012. International Code of Nomenclature for algae, fungi and plants (Melbourne Code): adopted by the Eighteenth International Botanical Congress Melbourne, Australia, July 2011. Regnum Vegetabile 154. Königstein: Koeltz Scientific Books [on line]. Disponible en: http:// www.iapt-taxon.org/nomen/main.php [Acceso 24 Noviembre 2017].

PETERSEN, O. G. 1890. Marantaceae. In: Martius, C. F. P., A. G. Eichler \& I. Urban (eds.), Flora Brasiliensis 3(3): 81-172. F. Fleischer, München.

PLUMIER, C. 1757. Plantarum americanarum fasciculus quintus: continens plantas, quas olim Carolus Plumierius, botanicorum princeps detexit, eruitque, atque in Insulis Antillis ipse depinxit. J. Burman, Amsterdam.

PRINCE, L. M. \& W. J. KRESS. 2006a. Phylogenetic relationships and classification in Marantaceae: insights from plastid DNA sequence data. Taxon 55: 281-296. 
PRINCE, L. M. \& W. J. KRESS. 2006b. Phylogeny and biogeography of the prayer plant family: getting to the root problem in Marantaceae. Aliso 22: 645-659.

SAKA, M. N. 2016. Revisão taxonômica e análises filogenéticas das espécies extra-amazônicas de Goeppertia Nees, clado Breviscapus (Marantaceae). Tesis doctoral. Universidad Estadual Paulista, "Julio de Mesquita Filho“, Instituto de Biociências, Rio Claro, São Paulo.

SASS, C., ILES, W. J. D., BARRETT, C. F., SMITH, S. Y. \& C. D. SPECHT. Revisiting the Zingiberales: using multiplexed exon capture to resolve ancient and recent phylogenetic splits in a charismatic plant lineage. PeerJ 4:e1584; DOI 10.7717/peerj.1584

SCHUMANN, K. 1902. Marantaceae. In: Engler, A. (ed.), Das Pflanzenreich (Heft 11) 4: 81-184.

SMITH, J. F, W. J. KRESS \& E. ZIMMER. 1993. A Phylogenetic analysis of the Zingiberales based on rbcl sequences. Ann. Missouri Bot. Gard. 80: 620630.

STAFLEU, F. A. \& R. S. COWAN. 1976-1988. Taxonomic Literature, vols. 1-7. International Association for Plant Taxonom, Utrecht.

SUKSATHAN, P., M. H. GUSTAFSSON \& F. BORCHSENIUS, F. 2009. Phylogeny and generic delimitation of Asian Marantaceae. Bot. J. Linn. Soc. 159: 381-395.

THIERS, B. 2018. Index Herbariorum: a global directory of public herbaria and associated staff. New York Botanical Garden's Virtual Herbarium [on line]. Disponible en: <http://sweetgum.nybg.org/ih> [Acceso 24 Noviembre 2017].

ULIANA, V. L. C. R. 2005. Levantamento preliminar do gênero Calathea G. Mey. para o neotrópico e revisão de Calathea G. Mey. sér. Comosae (Petersen) K. Schum. Tesis de doctorado. Universidad de São Paulo, São Paulo.
VIEIRA, S. R. 2005. Estudos filogenéticos e taxonómicos em Marantaceae, con ênfase em Maranta L. Tesis de doctorado, Universidad de São Paulo, São Paulo.

VIEIRA, S. R., P. J. M. MAAS \& F. BORSCHSENIUS. 2012a. Taxonomic revision of Myrosma (Marantaceae). Blumea 57: 125-130

VIEIRA, S., R. C. FORZZA \& M. G. L. WANDERLEY. 2012b. Marantaceae. In: M. G. L. Wanderley, S. E. Martins, R. P. Romanini, T. S. Melhem, G. L. Shepherd, A. M. Giulietii, J. R. Pirani, M. Kirizawa, M. M. R. F. Melo, I. Cordeiro \& L. S. Kinoshita (eds.), Flora Fanerogâmica do Estado de São Paulo 7: 205-232. Instituto de Botânica, São Paulo.

YOSHIDA-ARNS, K. N. 2003. Revisão taxonômica dos gêneros Ctenanthe Eichler e Stromanthe Sond. (Marantaceae). Tesis doctoral. Universidad Federal Rural de Pernambuco, Recife.

YOSHIDA-ARNS, K. N. \& S. J. MAYO. 2003. Tipificações em Ctenanthe Eichler (Marantaceae). Bradea 9: 11-16.

ZANOTTI, C. A., J. C. OSPINA \& C. M. MARTÍN. 2017. A new record in Argentina and lectotypification of Stromanthe boliviana K. Schum. (Marantaceae). Phytotaxa 332: 189-194.

ZULOAGA, F. O., O. MORRONE \& M. J. BELGRANO. 2008. Marantaceae. In: Zuloaga, F. O, O. Morrone \& M. J. Belgrano (eds.), Catálogo de las plantas vasculares del Cono Sur I. Monogr. Syst. Bot. Missouri Bot. Gard. 107: 470-471.

Recibido el 26 de abril de 2018, aceptado el 12 de julio de 2018. Editor: Diego G. Gutiérrez. 